\title{
Abseiling from the Shard: The Cognitive Foundations of Capability Development in Temporary Organizations
}

\author{
Chris Ford \\ Martin Friesl \\ Lancaster University Management School
}

\begin{abstract}
This paper focuses on capability development in temporary organizations. Prior research in such organizations problematizes but does not explicitly address the cognitive foundations of capability development, particularly with regard to actors' interpretation of organizational purpose, resources and capabilities. Drawing on the recent advances in research on the microfoundations of capability development we present an in-depth, longitudinal study of the run up to a large scale fundraising event. We propose a process model of capability development in temporary organizations that delineates how managerial cognition affects the accumulation of resources as well as the eventual assembly of organization level capabilities. This process model complements existing research on capability development in temporary organizations and provides new insights into the evolution of temporary organizations over time.

Keywords: temporary organisations, capability development, organisational purpose, microfoundations
\end{abstract}




\section{Introduction}

This paper investigates the development of capabilities in temporary organizations (TOs). TOs, such as projects, events or rescue operations require the collaborative action of multiple parties within a restricted timeframe (Bakker, 2010; Bakker, Defillippi, Schwab, \& Sydow, 2016; Bechky, 2006; Burke \& Morley, 2016; Grabher, 2004; Lanzara, 1983). Such organizations promise flexibility, efficiency and innovation benefits due to the development of specialized resources and capabilities for a specific and time-bound organizational purpose (Bechky, 2006; Engwall \& Westling, 2004; Grabher, 2004; Lundin \& Söderlund, 1995). Yet, this purpose is often only loosely defined, which adds to the existing challenge of developing capabilities within a short time period (Engwall \& Westling, 2004; Jones, Hesterly, FladmoeLindquist, \& Borgatti, 1998).

Prior studies already highlight the crucial relationship between purpose and capability but also point to an intricate aspect of this relationship that has remained unexplored. While an agreed-upon purpose is crucial for the identification of relevant resources (Grabher, 2004), actors' interpretations of what this purpose is (Lundin \& Söderlund, 1995) and what kinds of resources are required to fulfil it are negotiated and are likely to change over time (Engwall and Westling, 2004). In other words, capability development in TOs is underpinned by actors' changing interpretations and understandings of purpose as well as resources and capabilities. Yet, these 'cognitive' dynamics of capability development in temporary organizations have not been understood very well. Addressing this gap promises new insights into the development of highly specialized capabilities under severe time constraints as well as new explanatory means for the evolution of TOs more broadly.

In order to address this research gap we draw on recent advances relating to the microfoundations of capability development (Felin \& Foss, 2005; Felin, Foss, Heimeriks, \& Madsen, 2012). This perspective emphasizes the need to study capability development through the lens 
of individual interpretations, actions and interactions (Felin et al., 2012; Foss, 2011). We particularly draw on Eggers and Kaplan's (2013) model of capability development, for two reasons: firstly, it follows a theme within prior research on TOs (e.g. Grabher, 2004) which considers the assembly of resources crucial for the development of new capabilities; and secondly, this model differentiates between managerial cognition underpinning the development of resources and routines, and the creation of coordinated linkages between those resources in order to develop capabilities. Based on this perspective this paper answers the following research question: How does managerial cognition influence capability development in TOs over time?

Following other studies on capability development we chose a longitudinal, single case research design (Danneels, 2010; Montealegre, 2002). In particular, our analysis draws on a study of the nine-month run up to a high profile one-day fundraising event. The event offered donors the opportunity to abseil from 'The Shard' in London; at that time the tallest building in Western Europe. What started as a fairly small event soon became a very complex endeavour, involving the collaboration of a number of different organizations, representing a diverse set of organizational types, including (amongst others): the Duke of York, The Outward Bound Trust, the Royal Marines Commando, Mountaineering teams and Sellar Property Group.

Based on our analysis we develop a process model that delineates the role of managerial cognition in two interrelated cycles of capability development: the resource accumulation cycle and the capability assembly cycle. For each of these cycles we identify distinct types of managerial cognition. The process model explains the reciprocal relationship of purpose and resources and also highlights the role of capability level cognition as a crucial coordinating mechanism through which actors anticipate outcomes, create co-specialized roles and integrate resources in a temporal sequence. Moreover, this process model provides deep insights into 
two challenges TOs face: the drift of organizational purpose and, related to that, the development of tightly integrated capabilities, which lie at the heart of any potential efficiency gains promised by TOs.

Our paper complements existing research on capability development in TOs (e.g. Engwall \& Westling, 2004) by showing how the accumulation of resources and the assembly of capability are underpinned by managerial cognition. In particular, we develop a process model that differentiates between cognitive dynamics underpinning resource accumulation as well as capability assembly. Moreover, we add to extant research (Engwall, 2003; Grabher, 2004) by delineating the dialectic relationship between purpose and resource related cognition, providing new explanatory means for the evolution of TOs and the accumulation of resources. Finally, we provide new insights into the twin challenges of purpose drift and capability integration through the life of a temporary organisation, pointing out implications for management practice.

\section{Capability development in temporary organizations}

TOs allow individuals but also organizational actors to respond to quickly changing demands in the business environment, by flexibly combining expertise, resources and routines to pursue a particular task (Jones et al., 1998; Lundin \& Söderlund, 1995; Sydow, Lindkvist, \& DeFillippi, 2004). Drawing on Bakker (2010, p. 468) we define TOs as "a set of organizational actors working together on a complex task over a limited period of time". This implies that capabilities are assembled along a transient value chain, for a short period of time, before the TO is dissolved or reconfigured in order to pursue new objectives (Manning \& Sydow, 2011). Below we provide an overview of the state of research on capability development in TOs and then make the case for investigating the role of managerial cognition in this context. 


\section{State of existing research}

There are three perspectives on capability development in extant research on TOs: a learning perspective, an evolutionary perspective and an integrative perspective. We synthesize key insights from each perspective and, based on this, argue why research on TOs would benefit from investigating the interplay of organizational purpose and capability.

An important stream of research on TOs has focused on learning processes (JanowiczPanjaitan, Bakker, \& Kenis, 2009; Lindkvist, 2005). Studies taking a 'learning perspective' point out that experience and repetition are important capability building mechanisms (Engwall, 2003). For instance, Davies and Brady (2000) argue that firms develop the ability to manage TOs (such as project teams) if they frequently engage in initiating and implementing projects. In a later study they show how initial exploratory learning in the form of improvisation is superseded by exploitative learning as the firm applies prior experience to new projects (Brady \& Davies, 2004). In these studies TOs (e.g. projects) are realized 'within' a particular focal organization. The focal organization provides the structural means (such as functional roles and routines) to retain and make project experience available (Zollo \& Winter, 2002). Thus, this perspective largely focuses on a firm's ability to set up, run and orchestrate TOs internally rather than the development of specific (and potentially one-off) capabilities, whether internally or externally located, to fulfil the purpose of a project.

Another group of studies takes an 'integration perspective' on capability development. This second group of studies focuses on the identification and integration of resources within a TO, as a mechanism for capability development (Grabher, 2004). This perspective argues that TOs are embedded in organizational as well as wider social contexts. These contexts constitute an important source of resources and capabilities (Grabher, 2004; Sydow et al., 2004). These resources may include functional expertise, operating procedures and norms, but also aspects such as reputation and sources of legitimation (Engwall, 2003; Grabher, 2004). 
While these bundles of resources constitute a necessary condition for the very existence of a $\mathrm{TO}$, the efficacy of these organizations depends on the integration of those diverse resources (Grant, 1996) in order to create "seamless service experience for clients." (Jones et al., 1998, p. 399).

A third perspective also acknowledges the integration of multiple actors and resources but, in addition to that, focuses on the evolution of a focal TO over time and aims to understand how the integration of resources is achieved ('evolution perspective') (Lundin \& Söderlund, 1995). Despite the restricted duration of TOs (Lanzara, 1983), Bakker's (2010) and Burke and Morley's (2016) extensive reviews of the literature emphasize that TOs still exhibit characteristics of change as described in life cycle (Lundin \& Söderlund, 1995), group development (Saunders \& Ahuja, 2006), and punctuated equilibrium models (Engwall \& Westling, 2004; Gersick, 1988). While these studies do not explicitly study the development of capability, they still provide in-depth insights into the inner-workings of TOs. In particular, these studies reveal that the efficacy of these organizations is subject to the negotiation and enactment of clear role structures (Bechky, 2006), as well as the alignment of all parties around a shared objective (Engwall \& Westling, 2004). This is an important aspect. Prior research shows that partners in a TO might have diverging or even contradictory views about the purpose of this organization. Thus, rather than being pre-defined, actors negotiate and renegotiate the purpose of a TO (Jones et al., 1998).

The integration and evolutionary perspectives show how organizational capabilities in TOs emerge from the identification and integration of dispersed resources. In particular, evolutionary studies demonstrate that this integration requires the agreement of actors on a common purpose, some shared objective that the TO aims to achieve. While prior research suggests that purpose might not be pre-defined but negotiated (Engwall \& Westling, 2004; Jones et al., 1998), the interplay between purpose and capability development warrants a closer 
look. Indeed, in their seminal paper Lundin and Söderholm (1995) already highlight that organization members" "perceptions and cognitions" (p. 443) of the purpose or objective of the TO shape subsequent activities. Yet, the dynamic interactions between capability and purpose, and in particular their impact on capability development, have so far not been subject to explicit empirical research, and thus form the focus of this paper. In the next section we consider recent research on the cognitive foundations of capability development as a framework to study capability development in TOs.

\section{Capability development and managerial cognition}

Over the last decade, research on organizational capabilities has seen a shift towards disaggregating organization level phenomena (Johnson, Melin, \& Whittington, 2003) to understand the micro-level foundations, the inner workings, of capabilities (Felin et al., 2012; Parmigiani \& Howard-Grenville, 2011). The term 'micro-foundation' has been used to describe the individual level interpretations, actions and interactions together with the processes and structures that underpin the capability of the firm (Felin et al., 2012). For instance, micro-level studies have focused on the (re-) configuration of everyday activities (Salvato, 2003, 2009), motivation (Foss, 2011) or managerial agency (Howard-Grenville, 2005; Pandza, 2011; Parmigiani \& Howard-Grenville, 2011).

The notion of 'interpretation' is crucial as it highlights the role of cognition; the managerial interpretations that shape choices about capability development (Dionysiou \& Tsoukas, 2013; Laamanen \& Wallin, 2009; Tripsas \& Gavetti, 2000). Managerial cognition fundamentally influences the selection, development and orchestration of routines and resources towards a particular goal (Helfat \& Peteraf, 2003). In this paper, we particularly draw on Eggers and Kaplan's (2013) model of capability development. Similar to research on TOs (Grabher, 2004), they consider capability development as the assembly of routines and resources underpinned by managerial cognition. The cognitive processes that underpin the identification of purpose 
may include the pursuit of a business opportunity or the solution to fundamental strategic challenges the organization faces (Eggers \& Kaplan, 2013; Grégoire, Barr, \& Shepherd, 2010; Greve, 2003). Eggers and Kaplan (2013) particularly emphasize that the cognitive foundations of capability development refer to both the accumulation of building blocks for organization level capabilities (resources and routines), actors' understanding and interpretation of a firms purpose as well as assumptions about the capability of the organization as a whole. Capabilities are defined as the 'purposeful' integration and deployment of resources (Amit \& Schoemaker, 1993; Helfat \& Peteraf, 2003; Penrose, 1959). Eggers and Kaplan (2013) even argue that without purpose, there is no capability: “Until there is an interpretation of a capability's purpose, the organization possesses only a set of routines, knowledge, and assets and not capabilities per se" (p. 298).

Thus, the performance of organizations depends on how and to which purpose actors decide to deploy resources (Danneels, 2010). This resonates with the context of TOs. Here, resources are dispersed across multiple organizational actors, who are supposed to allocate resources into a temporally bounded organization. Yet, actors' individual and collective understandings of purpose and capability cannot be treated as a given. Rather, these are negotiated in organizations as actors raise potential problems or sense strategic opportunities (Eggers \& Kaplan, 2013; Teece, 2007). We use this literature on the cognitive foundations of capabilities as a theoretical foundation for our analysis and theory development, as we address the following research question: How do actors' understanding of purpose, resources and capabilities affect the development of capability development over time.

\section{Methodology}

In order to address the research question mentioned above we have adopted a qualitative, inductive methodology drawing on a longitudinal in-depth case analysis (Pratt, 2009; Yin, 2009). Longitudinal, single cases have a long tradition in research on capability development 
(Danneels, 2010; Laamanen \& Wallin, 2009; Montealegre, 2002). Below we introduce the research context for this study and explain our approach to data collection and analysis.

\section{Research context}

This paper traces the evolution of a large scale fundraising project initiated by The Outward Bound Trust ('TOBT'). TOBT is a charity that aims to give young people the opportunity for self-development and learning through activities in wild, natural outdoor environments. The charity has a head office in the north of England, a fundraising office in London and five main centres of activity - three in England, one in Wales and one in Scotland. The case we selected is a TO that existed for approximately 9 months in order to complete a fundraising abseil from the Shard, an iconic high rise building in the centre of London. We consider our context a typical case for the purposes of our theoretical developments: It is a complex, one-off event that brings together a number of stakeholders for a particular purpose, for a restricted period of time (Yin, 2009).

TOBT assembled a wide variety of stakeholders including: a member of the royal family in the UK, the military, a servicemen's charity, a youth charity, a commercial fundraising organization, a property developer and their building contractors, a sovereign wealth fund, a collection of mountaineering and high-rope stunt experts, and multiple participants in the oneday event that these stakeholders would collectively bring to life. Details of the key stakeholders and the roles they played are shown in Table 1.

\section{INSERT TABLE 1 HERE}

The mix of stakeholders, scarcity of resources and height of the building were amongst a number of factors that posed organizational and technological challenges that needed to be 
overcome. Our paper traces the run up to the actual event, from the formation of the TO to the day of execution and termination.

\section{Data collection}

Interviews: A total of 21 semi structured interviews were carried out throughout the project, including interviews with all stakeholder groups except the owners of the property, who did not want to participate. Of the 21 interviews, 16 took place during the project build up and 5 after completion. 16 interviews were transcribed verbatim, five were recorded in note form and written up immediately afterwards. Moreover, weekly informal conversations with TOBT's Head of Marketing allowed us to keep track of events. Interview data was crucial in order to analyse actors understanding of the purpose of the TO, the resources required and how they thought the various resources would work together during the abseil. Interview questions focused on understanding how actors perceived their and others' roles as well as the purpose of the organization.

Observational data: The first author participated in meetings that took place at the London fundraising office of the lead charity on the day that the mountaineers joined them from Scotland, 6 days prior to the abseil event. This allowed the researcher to observe and take audio notes of all actions and behaviours. Moreover, the first author was also invited to attend and take notes in the 2-hour meeting that took place between events, abseil and fundraising staff on that day. Observational data added an important context dimension which improved our ability to analyse the interview data (Shah \& Corley, 2006).

Documents: All project documents including feasibility studies, risk assessments, press releases, PR reports and presentations to the board of the property owners were provided. Updates were provided by email from the CEO of the lead charity on an ad-hoc basis, as events unfolded. In addition, the CEO made available copies of all significant email trails between himself and external stakeholders, throughout the project. Documents were particularly 
important in creating a timeline of key events but they also allowed us to evaluate the interpretations of actors at these particular points in time (Pentland \& Feldman, 2005).

\section{Data analysis}

Data analysis followed three main stages: Firstly we created a chronological account of events (briefly summarized in Table 3) that captured the different streams of activity, the actors and organizations involved, and how these integrated into the project at each particular point in time (Langley, 1999; Langley \& Tsoukas, 2010). Moreover, we also aimed at creating internally consistent phases that were clearly demarcated from previous and subsequent phases. Based on the chronology of events, we split the run up to the actual delivery of the event into four phases: Phase 1 describes the articulation of the initial purpose and the identification of resources. In Phase 2 actors start to envisage the interplay of these resources. Phase 3 sees a further accumulation of resources and continued planning towards the final event. Phase 4 describes the actual delivery of the abseil.

Secondly, for every phase we analysed actors understanding of purpose, resources and capabilities, as well as outcomes with regard to the resources accumulated and capabilities developed. Following Miles and Huberman's (1984) approach we used the theoretically derived concepts of purpose, resource and capability cognition as 'data bins' in order to inductively derive themes related to these categories. This is consistent with Shepherd and Sutcliffe's (2011) notion of inductive, top-down theorizing. We then compared these themes within phases and across phases. This resulted in the aggregation of themes to higher order constructs. This coding process was done collaboratively between the first and the second author in order to arrive at common theoretical themes with regard to managerial cognition. The second author played devil's advocate and so triggered further analysis and coding (Bartunek, FosterFishman, \& Keys, 1996). This analysis resulted in the identification of five types of managerial cognition (purpose (re-) articulation, resource framing, anticipating, co- 
specializing and integrating). Table 2 demonstrates the coding process and provides further supportive evidence.

Finally, in a third step we analysed the interplay of these types of cognition over time in order to develop a process model. Informed by Kaplan and Eggers (2013) this stage of analysis reveals two distinct cycles through which cognition affects the development of capability development: a resource accumulation cycle and a capability assembly cycle.

INSERT TABLE 2 HERE

\section{The temporary organisation: Abseiling from the Shard}

We present our findings as a sequence of four phases. These phases allow us to explore the events that unfolded during the life of the TO and give insights into the cognitive dynamics underpinning capability development. Throughout these phases, we highlight, in particular, the ways in which different interpretations of purpose, resources and capability are implicated in the process of capability development. To facilitate the reading of the case a summarised narrative timeline is shown in Table 3.

\section{INSERT TABLE 3 HERE}

\section{Phase 1: Resource accumulation cycle - Purpose articulation and resource framing}

In December 2011 TOBT's board of Trustees held its quarterly meeting in Buckingham Palace, presided over by their chairman, His Royal Highness the Duke of York ('HRH'). The trustee who acted as head of the organization's risk management committee, a widely respected and internationally renowned mountaineer and former CEO of the UK National Mountain Centre 
('the Mountaineer'), presented a paper showing three different options for a potential fundraising challenge.

\section{INSERT TABLE 3 HERE}

Initial purpose articulation: The event purpose was twofold: (1) to raise $£ 125,000$ for a specific boathouse building project at their Aberdovy centre in Wales, and (2) to foster greater team-working within the trustee group by actively engaging them in fundraising during a period of national economic austerity. The financial target originated from a donation made by a business local to Aberdovy, which offered to finance $50 \%$ of the boathouse build if TOBT sourced the balance. The event therefore needed to be challenging enough to allow them to attract sponsors, yet safe and accessible for the trustee group as a whole. The initial set of three options received a lukewarm reception, since the two UK events proposed were not terribly exciting or unique, and the foreign trip would rule out many people who could not afford the time away. The one advantage was that all events were manageable with their own resources and capabilities, utilising public spaces and well established processes. Then out of the blue HRH suggested that they abseil from The Shard. This more than fitted all of the requirements in terms of adventure and accessibility in that it was in the heart of London, where most trustees were based. It was agreed that HRH would pursue this idea with the manager and $20 \%$ part owner of the building, Irvine Sellar ('Sellar') of Sellar Property Group ('SPG').

Resource framing: It was well understood that it would be HRH's relationship with both Sellar and the Qatari owners of the other $80 \%$ of The Shard that would determine whether the essential resource - the building - could be made available to them: 
"The Shard had been approached over the last couple of years by every man and his dog for an abseil and it was only because of our Royal approach [..., ], that we got through the door" (CFO TOBT)

The initial purpose of the TO was based on a clear fundraising target and learning goals but no specific route and resources to achieving these. The decision to abseil from the Shard allowed the group to determine the resource requirements to make this happen:

"this situation has broken some of that normal process because really the ideas of fundraising activities and events would normally come from within the management structure [...]. In this case it dropped in from the Duke of York and then we picked it up to run and execute $[\ldots]$ " (CFO TOBT)

Central to these requirements was the hard-to-gain access to a prestigious and incomplete skyscraper as a key resource. To achieve access the organization needed the networking capabilities of $\mathrm{HRH}$, specifically his long established relationship with this building and its owners. Sellar owned just $20 \%$ of the building through his share in London Bridge Quarter ('LBQ'), the catch-all name for the Shard and the adjacent building projects. The other $80 \%$ stake was owned by the Qatari Investment Authority ('QIA'). HRH's role in securing this funding, and his wider role as a member of the UK Royal family, provided unique resource access where many others had previously been denied. However, the significance of the request meant that Sellar needed the approval of the board of LBQ, who in turn needed to see both a legitimate purpose and proven expertise from those who would be running the event.

Resource accumulation now rested on the actions and judgements of two main individuals: firstly, HRH would need to speak to Sellar and secure access to the building as a key resource; secondly, the Mountaineer needed to determine whether this abseil was both possible and safe, then convince the building owners that his assessment was well founded. However, in his judgement such an assessment required the engagement of additional, specific expertise in the 
form of a high ropes expert who had worked on a wide range of unusual challenges for television and film, all over the world.

Purpose (re-) articulation: This issue of being able to present a legitimate purpose to Sellar and LBQ was already evolving in the mind of $\mathrm{HRH}$. He had determined, unilaterally, that it would be a good idea for the Royal Marines to be involved alongside TOBT. This fitted with the agendas of many Royal fundraising events, which frequently support multiple charities. However, HRH wanted more than shared benefits, he wanted them involved.

"he was keen that they be involved in the heart of the project, Irvine's response to that was 'that would be fabulous because I'd really, you know, I love the story about Outward Bound but I also would like to be doing something that's sort of military too'. [...] I'm not convinced that without the Marines we would have got it over the line." (HRH Private Secretary)

The purpose has now considerably changed from TOBT's initial aims: to raise funds for building work, whilst engaging in team building activities for the board of trustees. The purpose now encompassed two additional elements: to raise funds for the Royal Marines Charitable Trust, for the benefit of injured soldiers, and to use the event as an opportunity to showcase the operational expertise of the Royal Marines Commandos.

Outcome of phase 1: By the end of phase 1 the initial purpose of fund raising and team building within a single charity had changed to include additional elements - raising funds for a second charity, the RMCT, whilst incorporating the fighting force of the Royal Marines into the event operations. Also, the team started to accumulate the resources necessary to make the event happen. This particularly involved the abseil expertise of TOBT's mountaineers and the Royal Marines, and the reputation and network of HRH. These resources, in turn, allowed further resource accumulation in the form of exclusive access to the Shard,

\section{Phase 2: Capability assembly cycle - Anticipating and co-specializing resource deployment}


The focus of phase 1 was on the accumulation of resources necessary in order to deliver a large scale, one-day fundraising event yet without a clear picture of how the various resources could be integrated. Phase 2 demarcates the transition from the accumulation of resources to the assembly of the abseil and fundraising capabilities. Below we describe three types of managerial cognition that underpinned the assembly of capability: anticipating, co-specializing roles and integrating.

Anticipating resource deployment: In anticipating the operational challenges ahead the Mountaineer and CEO of TOBT were faced with the technical challenge of designing and delivering a complex abseil, whilst integrating Marines capabilities into their own for the first time, as described by the CEO of TOBT below:

"I suppose it's the fact that the group, as stakeholders, has come together [...] without any background of having worked together or common culture to enable things to run more smoothly." (CEO TOBT)

This was all in the context of an event that needed to be created from first principles. It required anticipating new challenges and considering new pieces of equipment due to the distance to be covered, the weight of the ropes, the implications of the glass surface, the wind, the non-specialist participants and the limited time frame for the event (since the building was, at this time, still under construction).

“Every challenge that we're confronted with we've got to start afresh with new ideas. So whether it's an abseil off The Shard, whether it's going off a hot air balloon, we've just got to start with a clean sheet - you can't sort of come and say I've done this before it'll be OK." (High Ropes Expert).

In addition to the anticipation of operational challenges, the need to plan fundraising activities required managers to consider how they would work with both their new charity 
partners, the RMCT, as well as the owners of the building, their key contractors and marketing agents.

"I think Sellar Property Group this is their first foray into any kind of real fundraising venture. They haven't provided that level of clarity which makes it more difficult to work with them therefore you're pulling together the threads and trying to provide a level of leadership." (TOBT Project Manager).

The perception of the project manager was that it was particularly important for TOBT abseil and fundraising staff to anticipate all potential resource issues, and bring these to the attention of the expanded stakeholder group meetings that took place periodically at Buckingham Palace.

Co-specializing resource deployment: In February 2012 HRH convened a meeting at Buckingham Palace to determine the use of TOBT's and the Marines' resources. By this stage SPG had given provisional approval to the project, the Mountaineer and high ropes expert had visited the Shard and prepared a feasibility study, which Sellar incorporated into a proposal to the LBQ board in Doha. The Palace meeting was attended by two representatives from the Marines. On the abseil operational side the Royal Marines would be involved, and a Lieutenant Colonel was present to discuss this. On the fundraising side the Royal Marines Charitable Trust, an entirely separate legal entity managed by a retired Brigadier, were also in attendance. It became clear that the abseil capabilities of the two groups of experts, the Marines and the civilian TOBT mountaineers, were actually quite different and that the civilians were much better placed to take control:

"[...] this is out of grade working for them [...].this is a very complicated situation using equipment in a non-standard way. [...] We've spent a lot of time getting our heads around the best way to do this; the Marines don't have that level of experience." (Mountaineer) 
"whilst we do a lot of abseiling we don't do it from this sort of height, there isn't that requirement, and we certainly don't do an awful lot of it from a building. " (Marines PR)

The perception of the Mountaineer was that this event required the advanced problem solving and civilian oriented expertise of his team, not the Marines' military operational capabilities. He was concerned, however, that the Marines might be requested by HRH to lead the event without consideration of these differences. If such a request was made they would not be in a position to refuse.

If the Mountaineer had a better grasp of the specific differences in abseil capabilities, then HRH had the wider understanding of the importance of the legitimation provided by Marines involvement. This played an important part in securing necessary resources, since HRH knew that satisfying the agendas of resource providers was essential to the maintenance of good relations and resource access.

"There was always a bit of tension between the Duke and if you like the Outward Bound climbers as to who had the best skills in terms of doing the actual abseiling. And [the CEO] quite rightly maintained that [the Mountaineer] and his team absolutely are experts at that. But the Duke's view and I'm, having sort of sat through it all now I think was correct, was that it's a more powerful story where you've got the military alongside it." (HRH's private secretary)

Outcome of phase 2: By the end of phase $2 \mathrm{HRH}$, The Royal Marines, and the Mountaineer come together with the new, shared understanding of purpose and an initial understanding of how the various parties could work together. The Mountaineer took a firm stance in the negotiations, and insisted that he either led the event or handed it to the Marines entirely. The abseil expertise of the Marines was considered unsuitable for such a bespoke, civilian event. It was agreed that he and his team would take control, whilst the Marines would deliver the preevent training and take an active supporting role on the day. 


\section{Phase 3: Interplay of resource accumulation and capability assembly cycles}

The increasing public relations focus of the event led to the identification of resource gaps. As a result, in phase 3 additional marketing and PR resources were acquired, while the cospecialization and integration of resources continued.

Resource framing: For SPG the event was potentially of great PR value. Thus, the incorporation of PR outcomes into the purpose of the organization needed to be crystallized into some form of actionable PR strategy. Publicity was the principle value that would be captured by SPG (they would not be recipients of any fundraising), yet they were also most at risk in terms of bad press if anything went wrong.

"The value they want from it is very different from what the Trust wants from it, they want the PR whereas the Trust wants effectively the fundraising, so they need to manage the PR because that's the bit that is of most interest to them" (Project Manager)

Thus, rather than relying on the in-house marketing team an invitation was extended to P-AR (name changed) to provide assistance, pro-bono. P-AR already had many links to LBQ and $\mathrm{HRH}$, so was well aware of the value of donating their extensive PR resources to this cause. "it's yet another voice around the table [...]. And again supremely disinterested in the cause, more interested in actually pleasing the Duke and ideally in pleasing the Qatari's because they have the Qatari Royal family as one of their clients as well." (CEO TOBT) Subsequent meetings at the palace included a P-AR director and SPG marketing manager. These meetings created a greater focus on the publicity generating aspects of the events' purpose.

Purpose (re-) articulation: Within TOBT some differences of opinion developed over the importance of value creation through event related PR. This was highlighted when a trustee of TOBT suggested that they might enter into an agreement with a television company, a major celebrity and a different charity to raise funds and produce a documentary. To do this would 
have placed even greater importance on the emergent PR aspect of purpose, whilst introducing other stakeholders (such as news media) whose agendas would have to be acknowledged. The CEO of TOBT, however, was more tightly focussed on fundraising:

"the purpose of this event for TOBT is to raise money for bursary purposes. That's its primary and really only purpose [...]as soon as we get into these peripheral conversations about what people need to achieve for their own purposes we haven't really given them much hearing. You know it's got to be really clear with people this is about raising money." (CFO TOBT)

Despite this belief about the core purpose from the executive of the charity, it was well understood that to raise this money, they needed to support the achievement of other aspects of purpose, those of importance to other key stakeholders.

Co-specializing PR and fundraising resources: The CEO of TOBT instructed the PR person from TOBT to not attend further meetings at the palace, to engage in other negotiations with third parties, or get involved until much closer to the actual event. Another potential tension arose from the very high levels of expected fundraising being set, with minimum donations of $£ 25,000$ being requested due to the magnitude of the event and the limited number of places available. For wealthy trustees or those with strong donor networks this sum was achievable, but for others it might not be. This minimum therefore created a tension between the need for maximum fundraising versus the need for full participation as part of a teambuilding experience, an aspect of the initial purpose that had been pushed into the background.

"At various points it looked as if the role of the Trustees was going to be forgotten in this, in the urge to get more money out of other people for doing the same thing. [We] had to repeatedly re-insert the broader challenge aspects of this back into it." (Member Board of Trustees) 
Ultimately the solution was a redefining of 'participation' to include hands-on involvement of some trustees in the management of the event, without actually abseiling or fundraising themselves.

Resource framing: While TOBT needed to agree on how to coordinate PR resource across organizations, the two charity CEOs also understood that they needed to reach some agreement on how to deploy fundraising resources. Yet, with no history of working together they had only a limited understanding of each other's capacity and expertise. The fundraising Director of TOBT believed that the RMCT had limited fundraising expertise and a small donor network, and should therefore hand over all responsibilities to his team. This would allow both charities to benefit from the high level of expertise within TOBT for exclusive, royally connected events. However, his proposal placed a cap on RMCT earnings, since his belief was that TOBT, as the originators of the event and providers of the essential fundraising resources, should benefit solely from any extraordinary gains.

Integrating fundraising resources: The RMCT were hesitant about this agreement. Thus, for reasons of simplicity, the CEO of TOBT took a direct interest in the discussions. He agreed with the Lieutenant Colonel of the Marines that TOBT would take 12 long and 12 short ropes to 'sell' to their contacts while the Marines took 7 of each. The final full abseil (long plus short rope combined) was for HRH, whose fundraising would be split equally between the charities. This effectively removed the issue of integrating fundraising resources across charities, instead allocating fixed amounts of ropes to each separate organization's fundraising departments to ‘sell'.

This approach created a capability issue for the RMCT, who engaged the services of Commando Spirit, a private fundraising organization that was already working for them on a separate appeal. However, Commando Spirit had limited networks, so its approach to 
fundraising was based on a model of much wider public engagement and grass-roots support for events with less ambitious financial targets. There were other challenges, too:

"the main difference between this and what we've done before was the time scale. So as I said, a month to recruit. These sorts of events we usually take 18 months to 12 months....The number of stakeholders, that was another big difference, and having a charity partner, we hadn't worked with a charity partner before." (CEO of Commando Spirit)

This explains the very different perceptions of the potential value of this event, evidenced by the fundraising targets: $£ 1 \mathrm{~m}$ for TOBT and $£ 150 \mathrm{k}$ for Commando Spirit, with a minimum donation for long ropes of $£ 100,000$ for TOBT and $£ 25,000$ for Commando Sprit.

Outcome of phase 3: By the end of phase three the resource portfolio underpinning the event had grown substantially. A major PR agency was appointed to work on the project, guided primarily by the requirements of HRH and SPG. Also, RMCT appointed Commando Spirit to manage their fundraising operations. TOBT now have fewer "ropes" to sell but with the ability to generate $100 \%$ of the income from those ropes for themselves, through exploitation of their own fundraising networks. The importance of the team building element for TOBT's board, which formed a core element of the initial purpose, was now just one element of a much more wide-ranging organisational purpose.

\section{Phase 4: Co-specializing and integrating resources for final capability performance}

At 4am on Monday morning the Mountaineer, High Ropes Expert, three other mountaineering experts and the SPG security advisor unloaded their gear at the base of the Shard. They were about to attempt the highest civilian abseil in history, using descending equipment specially designed for this event. With $175 \mathrm{~m}$ of descent in a single stage the use of standard equipment could have been disastrous for a number of reasons: a free hanging rope could snap under its own weight or catch the wind and send the abseiler crashing round to the wrong face of the 
building, while standard descending metalwork could overheat and burn clean through the rope. This was pointed out by a Marines specialist:

"you would have to come down at a very controlled speed and you would probably have to stop every few metres, because if you generated too much heat and then stopped you'd burn through the rope and you'd drop off'" (Marines PR)

Integrating resources for the abseil: At the Shard, London's newest landmark building, the mountaineering team met up with the Marines who would be working with them for the day. Together they proceeded to the $87^{\text {th }}$ floor to begin their setup. Next to arrive were staff and trustees from TOBT along with more Marines, who would be the event management and support team. Quite a number of the 40 participants had last minute requests, like go-pro cameras they wanted secured onto their helmets and body armour for knees and elbows fitted. These last items were purchased in haste the day before, after it was discovered on Saturday that the outside glass faces were not only very slippery in morning dew but also there were far more sharp protrusions than expected. That had been the first time the team were allowed to see or experience the outside of the building - just $48 \mathrm{hrs}$ before the main event.

'Saturday is 'everything day' for us [...] that's the only chance we get to rig the ropes.

That's the only chance we get to run through the abseil. It's the only chance we get to convince the people at The Shard that it's safe" (Mountaineer)

Despite this short time window to complete their preparations, the Mountaineer had sufficient slack in the resources available to him to permit TOBT fundraising staff to recruit two additional participants at the very last minute. This addition required the running of a full training programme on Sunday, staffed by two of the civilian mountaineering team, provision of equipment and clothing and comprehensive medical checks, all to secure their participation and combined $£ 200,000$ donation to charity. 
Co-specializing logistics resources: The event timelines were incredibly tight and everything had to flow with military precision. The original management plan devised by TOBT had been reviewed and improved by Marines logistics, which provided marshals for the participants themselves. Each participant arrived at the hotel next to The Shard, changed into the clothing and non-marking footwear specifically selected by the mountaineering team and was then escorted to the Shard. Here they entered an equipping and kit checking stage on the $14^{\text {th }}$ floor before proceeding to the top of the buildering on the $87^{\text {th }}$ floor to go through the predeparture "Safety Flow Protocol". Internally, the Shard was still a building site, so all participants had to be escorted by event staff, who had been inducted by SPGs agents on building safety a few days earlier.

Outcome of phase 4 - The Abseil: All of this took place in the direct glare of the media; with a national news film crew on the top of the building and two news helicopters above, ready to film $\mathrm{HRH}$ who would descend first at 7am. The first stage of the descent went from the $87^{\text {th }}$ to $78^{\text {th }}$ floor, where Marines were ready to pull the participants back inside to change ropes. This changeover was necessary because the height of the building meant that the abseil had to take place over three stages, re-entering the building through removed windows on both the $78^{\text {th }}$ and $29^{\text {th }}$ floors. Participants ultimately landed on the flat roof of the $20^{\text {th }}$ floor, on a small extension to the main building. On this roof there were press reporters, photographers and PR staff from all the major stakeholders. By the end of the day the participants had raised a combined total of $£ 2.7 \mathrm{~m}$, which after costs yielded a net income of $£ 2 \mathrm{~m}$ for TOBT and $£ 0.5 \mathrm{~m}$ for RMCT.

\section{The cognitive foundations of capability development in temporary}

\section{organizations: A process model}

This paper provides insights into the cognitive foundations of capability development in TOs. Based on our findings presented above we propose a process model that illuminates how 
managerial cognition influences the accumulation of resources and the development of organizational capabilities in TOs (see Figure 1). This process model also provides insights into important challenges of capability development in temporary organizations.

\section{INSERT FIGURE 1 HERE}

Our findings show that capability development in TOs can be described by two interrelated cycles of managerial cognition: a resource accumulation cycle and a capability assembly cycle. The resource accumulation cycle involves the creation of a portfolio of resources necessary to pursue the purpose of a TO. We use the notion of resources broadly defined, encompassing valuable knowledge, routines, individual skills or reputation, etc. (Barney, 1991). The capability assembly cycle describes the coordinated integration of these resources towards fulfilling the purpose of the organization. Table 4 provides an overview of each type of cognition implicated in capability development through these two inter-related cycles.

\section{INSERT TABLE 4 HERE}

Resource accumulation cycle: At the heart of the resource accumulation cycle is managerial cognition with regard to the articulation and re-articulation of organizational purpose as well as the framing of resources required to fulfil this purpose. Our findings suggest that purpose articulation and resource framing are in a dialectic relationship as changes in resource framing might influence the very purpose of the organization and vice versa. This is evident in phase 1 . The initial 2-part purpose of raising funds and team building resulted in the framing of the resources required, including access to the shard, which in turn required the involvement of the Royal Marines and the embedding of their fundraising and PR needs into 
an augmented overall purpose. Moreover, this dialectic relationship is also manifest in phase 3. As SPG's interest lay in PR for the Shard, the capability framing highlighted a need for advanced PR skills, which eventually resulted in the participation of a PR agency. Indeed, as actors gain further understanding of the resources required they also realize what additional purpose could be achieved by leveraging those resources. Thus, the interplay of purpose articulation and resource framing might result in deliberate, but also potentially unintended, departures from the initial purpose.

The cognitive dynamics underpinning the resource accumulation cycle point towards an important challenge for TOs. While this purpose-specific assembly of capabilities is the main virtue of this organizational form it may also result in purpose drift; the unintended expansion and/or change of purpose over time. Required resources cannot always be acquired in pure form, they come attached to stakeholders with their own agendas that may need to be integrated into the organisation's purpose. Thus, on the one hand TOs are bundles of resources and capabilities. On the other, they are also complex configurations of political agendas that need to be balanced. This has two important implications: First, these agendas may result in the expansion of organizational purpose, with associated tensions regarding the balance and rank order of objectives. Second, purpose drift may drive the accumulation of resources resulting in ever more complex cycles of purpose articulation. This highlights a substantial challenge for TOs: Escalating cycles of purpose articulation that put the timely delivery of TOs at risk.

Capability assembly cycle: The tentative agreement on a shared purpose demarcates the transition from the resource accumulation cycle to a cycle of capability assembly, underpinned by three types of managerial cognition: anticipating, co-specializing and integrating. Rather than focussing on purpose and the types of resources required, actors are now concerned with coordinating the interplay of these resources towards the delivery of purpose. Once a shared understanding of organizational purpose has been reached (even tentative), actors engage in 
anticipating the delivery of this purpose. Anticipating requires actors to envisage the interplay of various resources in practice and the potential challenges that might arise. This is evident in phase 2, when actors used a number of meetings at Buckingham palace to discuss how the various resources, such as the Mountaineers, the Marines etc. could potentially work together. This also leads to the co-specialization of roles in order to work out 'who' is doing 'what' and the related dependencies. The case suggests that this process of co-specializing might actually reveal resource gaps, which then triggers a further cycle of resource accumulation. For instance, in phase 2 actors realized that the abseil approach of the Marines would not be appropriate to abseil from a building as tall as the Shard. Finally, capability assembly is characterized by managerial cognition with regard to the integrating of resources. This involves the development of mutual knowledge across all stakeholders focussed on the coordinated and sequenced interplay of actors. This is particularly evident in phase 4, when all parties meet prior to the event in order to go through the motions and prepare for the abseil. Yet, the capability assembly is not a linear process. Any operational issues occurring in the process of capability performance may trigger further cycles of co-specialization and integration.

Moreover, any drift or unintended expansion of purpose occurring during the resource accumulation cycle may affect the assembly of capabilities in TOs. The case presented above suggests that while actors initially strive to integrate capabilities towards the delivery of the organizational purpose, purpose drift potentially results in the separation of capabilities. This may come about either through a decision to avoid integration in the face of an increasingly complex and multi-faceted purpose, or an acceptance that integration would be too difficult to achieve given the time-bound nature of the organization. As a result, capability separation leads to the de-facto fragmentation of a TO. Indeed, TOBT and the Royal Marines ultimately did not integrate their fundraising teams or any of their fundraising activities. Also, TOBT and the Marines split the ropes, each offering their own ropes to their own participants at their own 
prices. While the event exceeded expectations with regard to money raised as well as PR value, TOBT management raised the issue that the full potential of this event may not have been achieved.

\section{Theoretical implications}

This paper contributes to the growing body of research on TOs by particularly emphasizing the cognitive foundations of capability development in these organizations. Below we discuss our theoretical contributions in greater detail.

First, the process model developed in this paper provides new insights into the cognitive underpinning of capabiltiy development in TOs. An important argument of previous research in the capability based view of the firm as well as in research on TOs has been that 'capability' is only accomplished if a portfolio of resources can be assembled towards a particular purpose (Amit \& Schoemaker, 1993; Engwall \& Westling, 2004; Grant, 1996). One important cognitive mechanism through which this assembly is accomplished is via experience (Zollo \& Winter, 2002). Managers' experience leaves an imprint on the capability of the organization and vice versa in a co-evolutionary process (Eggers \& Kaplan, 2013; Engwall \& Westling, 2004; Laamanen \& Wallin, 2009). However, this becomes problematic in TOs created for specific, one-off events, such as the Abseil from the Shard, where stakeholders are coming together for the first time. In such cases there is no opportunity to gain experience of the interplay of all the stakeholders involved prior to the actual event. In contrast, our findings suggest that in such instances, capability assembly via experience is replaced by other cognitive mechanims such as the anticipation of the collaborative process (at a particular point in time in the future), the co-specialization of roles (i.e. the complementary or overlapping activities the various stakeholders are able to perform) and the temporal integration of such roles. Thus, rather than being based on the accumulation of experience over time, capability assembly under severe time constraints may be confined to the establishment of a shared understanding (Dionysiou \& 
Tsoukas, 2013; Eggers \& Kaplan, 2013; Feldman \& Pentland, 2003). This understanding may encompass the objective of the organization, the types of resources enrolled and their cospecialized and integrated interplay. These findings answer the call in research on TOs to better understand the role of temporariness in how these organizations function (Janowicz-Panjaitan et al., 2009).

Second, the dialectic relationship between purpose articulation and resource framing provides new explanatory means for the resource accumulation stage of capability development in TOs. Prior research already shows that the purpose of TOs is negotiated and evolves over time (Jones et al., 1998) and that the resources accumulated are a mechanism to achieve legitimacy for a particular purpose (Engwall, 2003; Grabher, 2004). Our findings confirm but also compelement Engwall (2003) and Grabher (2004) by showing that the renegotation of purpose is strongly linked to changes in the resource portfolio of a TO. Indeed, the Shard case illustrates that resources, such as the abseiling capabilty of the Royal Marines Commando, or the access to the Shard granted by SPG, required TOBT to accommodate the respective 'agendas' of these organizations by adjusting the purpose of the event. As the purpose evolved so did the resource requirements to fulfil this purpose. Thus, by acknowledging this political dimension of organizational resources, we provide new explanatory means for how TOs evolve.

Third, by unpacking the cognitive dynamics underpinning the resource accumulation and capability assembly cycles we provide further insights into the challenges of TOs and the potential reasons for disruption and inefficiencies in this organizational form. Prior studies argue that the efficacy of TOs depends on the integration of a portfolio of resources and capabilties (Grant, 1996; Jones et al., 1998). Our studies shows that purpose drift is an important challenge to this integration. While managerial cognition in the capability assembly cycle is aimed at integrating, our findings also suggests that organizational purpose might 
require the deliberate separation of organizational capabilties. For instance, in the Shard case managers at TOBT and the Marines decided to separate both the operational expertise of the Mountaneer and Marines, with one running the main event and the other the training days, as well as the resources (the ropes) required for fundraising, and the fundraising capabilties themselves. They created two de-facto organizations under the umbrella of TOBT's fundraising event. Moreover, purpose drift is a challenge in its own right. The fragmentation of organizational purpose puts further strain on an organization that is already constrained by its temporary boundedness. In other words, compared to ordinary organizations, TOs are limited in their ability to cope with and absorb purpose drift.

\section{Conclusion}

The proliferation of TOs raises the importance of understanding how those organizations develop capabilities.. By unravelling the cognitive foundations of capabililty development in TOs we open up new avenues for future research.

The proposed process model draws attention to the crucial and interrelated cycles of resource accumulation and capability assembly, and how they are underpinned by different forms of managerial cognition. Through greater insight into the development of a shared understanding of how resources are integrated and sequenced we can better investigate the challenges, opportunities and managerial capabilities implicated in the successful accomplishment of temporary organisations. Our findings already suggest that the nature of the accumulation cycle may depend on the extent to which actors in a TO can gain direct experience in the interplay of resources. The influence of the degree of permanancy of TOs on how these organizations operate has been highlighted in a recent research (Bakker et al., 2016; Janowicz-Panjaitan et al., 2009). Thus, we encourage future research to investigate the capabilty accumulation cycle in different types of temporal organizations. 
Our findings also have implications for management practice. While a shared understanding of purpose is crucial in order to assemble resources into capabilities, the communication of purpose is critical. In order to mobilize actors towards a common purpose, any formulation of purpose needs to be carefully worded and needs to be sufficiently broad and maleable in order to allow actors to pursue their individual agendas; otherwise, TOs might fail due to a lack of consensus (Baier, March, \& Saetren, 1989). As neither purpose nor organizaitonal capabilities are fixed, but evolve and interact through the life of the temporary organisation, this shared understanding needs to be constantly revisited, to ensure that important agendas are maintained while new opportunities are evaluated and pursued. 


\section{References}

Amit, R., \& Schoemaker, P. J. H. 1993. Strategic assets and organizational rent. Strategic Management Journal, 14(1): 33-46.

Baier, V. E., March, J. G., \& Saetren, H. 1989. Implementation and Ambiguity. In J. G. March (Ed.), Decisions and Organizations: 150-164. Basil Blackwell: Oxford.

Bakker, R. M. 2010. Taking Stock of Temporary Organizational Forms: A Systematic Review and Research Agenda. International Journal of Management Reviews, 12: 466-486.

Bakker, R. M., Defillippi, R. J., Schwab, A., \& Sydow, J. 2016. Temporary Organizing: Promises, Processes, Problems. Organization Studies, 37(12): 1703-1719.

Barney, J. 1991. Firm resources and sustained competitive advantage. Journal of Management, 17(1): 99-120.

Bartunek, J. M., FosterFishman, P. G., \& Keys, C. B. 1996. Using collaborative advocacy to foster intergroup cooperation: A joint insider-outsider investigation. Human Relations, 49(6): 701733.

Bechky, B. A. 2006. Gaffers, Gofers and Grips: Role Based Coordination in Temporary Organizations. Organization Science, 17(1): 3-21.

Brady, T., \& Davies, A. 2004. Building project capabilities: from exploratory to exploitative learning. Organization Studies, 25: 1601-1621.

Burke, C. M., \& Morley, M. J. 2016. On temporary organizations: A review, synthesis and research agenda. Human Relations, 69(6): 1235-1258.

Danneels, E. 2010. Trying To Become a Different Type of Company: Dynamic Capability at Smith Corona. Strategic Management Journal, 32: 1-31.

Davies, A., \& Brady, T. 2000. Organisational capabilities and learning in complex product systems: towards repeatable solutions. Research Policy, 29: 931-953.

Dionysiou, D. D., \& Tsoukas, H. 2013. Understanding the (Re)Creation of Routines from Within: A Symbolic Interactionist Perspective. Academy of Management Review, 38(2): 181-205.

Eggers, J. P., \& Kaplan, S. 2013. Cognition and Capabilities. The Academy of Management Annals, 7(1): 293-338.

Engwall, M. 2003. No project is an island: linking projects to history and context. Research Policy, 32: 789-808.

Engwall, M., \& Westling, G. 2004. Peripety in an R\&D Drama: Capturing a turnaround in Project Dynamics. Organization Studies, 25(9): 1557-1578.

Feldman, M. S., \& Pentland, B. T. 2003. Reconceptualizing organizational routines as a source of flexibility and change. Administrative Science Quarterly, 48(1): 94-118.

Felin, T., \& Foss, N. J. 2005. Strategic organization: A field in search of micro-foundations. Strategic Organization, 3: 441-455.

Felin, T., Foss, N. J., Heimeriks, K. H., \& Madsen, T. L. 2012. Microfoundations of routines and capabilities: Individuals, processes, and structure. Journal of Management Studies, 49(8): 1351-1374.

Foss, N. 2011. Why micro-foundations for resource-based theory are needed and what they may look like. Journal of Management, 37(5): 1413-1428.

Gersick, C. J. G. 1988. Time and Transition in Work Teams - toward a New Model of Group Development. Academy of Management Journal, 31(1): 9-41.

Grabher, G. 2004. Temporary Architectures of Learning: Knowledge Governance in Project Ecologies. Organization Studies, 25(9): 1491-1514.

Grant, R. M. 1996. Toward a knowledge-based theory of the firm. Strategic Management Journal, 17: 109-122.

Grégoire, D. A., Barr, P. S., \& Shepherd, D. A. 2010. Cognitive Processes of Opportunity Recognition: The Role of Structural Alignment. Organization Science, 21(2): 413-431. 
Greve, H. R. 2003. A Behavioral Theory of R\&D Expenditures and Innovations: Evidence from Shipbuilding. Academy of Management Journal, 46(6): 685-702.

Helfat, C. E., \& Peteraf, M. A. 2003. The dynamic resource-based view: Capability lifecycles. Strategic Management Journal, 24(10): 997-1010.

Howard-Grenville, J. A. 2005. The persistence of flexible organizational routines: The role of agency and organizational context. Organization Science, 16(6): 618-636.

Janowicz-Panjaitan, M., Bakker, R. M., \& Kenis, P. 2009. Research on temporary organizations: The state of the art and distinct approaches toward 'temporariness'. In P. Kenis, M. JanowiczPanjaitan, \& B. Cambré (Eds.), Temporary Organizations - Prevalence, Logic and Effeciveness: 56-85. Cheltenham: Edgar Elgar.

Johnson, G., Melin, L., \& Whittington, R. 2003. Micro strategy and strategizing: Towards an activitybased view. Journal of Management Studies, 40(1): 3-22.

Jones, C., Hesterly, W. S., Fladmoe-Lindquist, K., \& Borgatti, S. P. 1998. Professional Service Constellations: How Strategies and Capabilities Influence Collaborative Stability and Change. Organization Science, 9(3): 396-410.

Laamanen, T., \& Wallin, J. 2009. Cognitive dynamics of capability development paths. Journal of Management Studies, 46(6): 950-981.

Langley, A. 1999. Strategies for theorizing from process data. Academy of Management Review, 24(4): 691-710.

Langley, A., \& Tsoukas, H. 2010. Introducing perspectives on process organization studies. In T. Hernes, \& S. Matilis (Eds.), Process, sensemaking, and organizing: 1-26. Oxford: Oxford University Press.

Lanzara, G. F. 1983. Ephemeral Organizations in Extreme Environments: Emergence, Strategy, Extinction. Journal of Management Studies, 20(1): 71-95.

Lindkvist, L. 2005. Knowledge communities and knowledge collectivities: A typology of knowledge work in groups. Journal of Management Studies, 42(6): 1189-1210.

Lundin, R. A., \& Söderlund, A. 1995. A theory of temporary organization. Scandinavian Journal of Management, 11(4): 437-455.

Manning, S., \& Sydow, J. 2011. Projects, paths, and practices: sustaining and leveraging projectbased relationships. Industrial \& Corporate Change, 20(5): 1369-1402.

Miles, M. B., \& Huberman, A. M. 1984. Qualitative data analysis. A sourcebook of new methods. London: Sage.

Montealegre, R. 2002. A process model of capability development: Lessons from the electronic commerce strategy at Bolsa de Valores de Guayaquil. Organization Science, 13(5): 514-531.

Pandza, K. 2011. Why and How Will a Group Act Autonomously to Make an Impact on the Development of Organizational Capabilities? Journal of Management Studies, 48(5): 10151043.

Parmigiani, A., \& Howard-Grenville, J. 2011. Routines Revisited: Exploring the Capabilities and Practice Perspectives. The Academy of Management Annals, 5(1): 413-453.

Penrose, E. T. 1959. The theory of the growth of the firm. New York,: Wiley.

Pentland, B. T., \& Feldman, M. S. 2005. Organizational routines as a unit of analysis. Industrial and Corporate Change, 14(5): 793-815.

Pratt, M. G. 2009. For the Lack of a Boilerplate: Tips on Writing up (and Reviewing) Qualitative Research. Academy of Management Journal, 52(5): 856-862.

Salvato, C. 2003. The role of micro-strategies in the engineering of firm evolution. Journal of Management Studies, 40(1): 83-108.

Salvato, C. 2009. Capabilities unveiled: The role of ordinary activities in the evolution of product development processes. Organization Science, 20(2): 384-409.

Saunders, C. S., \& Ahuja, M. K. 2006. Are all distributed teams the same? Differentiating between temprary and ongoing distributed teams. Small Group Research, 37: 662-700. 
Shah, S. K., \& Corley, K. G. 2006. Building better theory by bridging the quantitative-qualitative divide. Journal of Management Studies, 43(8): 1821-1835.

Shepherd, D. A., \& Sutcliffe, K. M. 2011. Inductive top-down theorizing: A source of new theories of organization. Academy of Management Review, 36(2): 361-380.

Sydow, J., Lindkvist, L., \& DeFillippi, R. 2004. Project-Based Organizations, Embeddedness and Repositories of Knowledge: Editorial, Organization Studies, Vol. 25: 1475-1489.

Teece, D. J. 2007. Explicating dynamic capabilities: The nature and microfoundations of (sustainable) enterprise performance. Strategic Management Journal, 28(13): 1319-1350.

Tripsas, M., \& Gavetti, G. 2000. Capabilities, cognition, and inertia: Evidence from digital imaging. Strategic Management Journal, 21(10-11): 1147-1161.

Yin, R. K. 2009. Case study research: Design and methods (4th ed.). Los Angeles: Sage Publications. Zollo, M., \& Winter, S. G. 2002. Deliberate learning and the evolution of dynamic capabilities.

Organization Science, 13(3): 339-351. 


\section{Figures and Tables}

Table 1 Key Stakeholders (In order of appearance)

\begin{tabular}{|c|c|}
\hline Stakeholder & Description and role(s) \\
\hline $\begin{array}{l}\text { The Outward Bound Trust } \\
\text { ('TOBT') }\end{array}$ & $\begin{array}{l}\text { A UK-based educational charity, headquartered in Cumbria, that aims to give } \\
\text { young people the opportunity for self-development and learning through } \\
\text { activities in wild, natural outdoor environments. }\end{array}$ \\
\hline $\begin{array}{l}\text { His Royal Highness Prince } \\
\text { Andrew the Duke of York } \\
\text { ('HRH') }\end{array}$ & $\begin{array}{l}\text { Second son of Queen Elizabeth II, the current Queen of the United Kingdom. } \\
\text { Also the Chairman of the Board of Trustees of TOBT }\end{array}$ \\
\hline 'The Mountaineer' & $\begin{array}{l}\text { Expert mountaineer, a member of the TOBT Trustee Board, and head of the } \\
\text { TOBT Risk Management Committee. }\end{array}$ \\
\hline $\begin{array}{l}\text { Irvine Sellar ('Sellar') and the } \\
\text { Sellar Property Group ('SPG') }\end{array}$ & $\begin{array}{l}\text { Property entrepreneur and founder of the property group in his own name. } \\
\text { Originally commissioned the design and construction of The Shard, and } \\
\text { maintains operational control although now with only a } 20 \% \text { ownership stake. } \\
\text { Irvin Sellar died on } 26^{\text {th }} \text { February } 2017 \text {. }\end{array}$ \\
\hline $\begin{array}{l}\text { Qatari Investment Authority } \\
\text { ('QIA') and London Bridge } \\
\text { Quarter ('LBQ') }\end{array}$ & $\begin{array}{l}\text { The QIA is the world's largest sovereign investment fund. It owns } 80 \% \text { of The } \\
\text { Shard, held through its ownership of LBQ, which holds additional real estate } \\
\text { in the London Bridge area. }\end{array}$ \\
\hline 'The High Ropes Expert' & $\begin{array}{l}\text { Internationally renowned expert in the design and delivery of unusual and } \\
\text { challenging high ropes activities for film and television. }\end{array}$ \\
\hline The Royal Marines & $\begin{array}{l}\text { The Royal Marines are the amphibious troops of the Royal Navy, } \\
\text { acknowledged as one of the world's elite commando forces. }\end{array}$ \\
\hline $\begin{array}{l}\text { Royal Marines Charitable Trust } \\
\text { ('RMCT') }\end{array}$ & $\begin{array}{l}\text { A registered charity, operated independently of the Royal Marines, dedicated } \\
\text { to supporting both serving and retired marines and their families. }\end{array}$ \\
\hline $\begin{array}{l}\text { Public Relations Agency } \\
\text { ('P-AR') }\end{array}$ & $\begin{array}{l}\text { A large, international PR agency headquartered in London, with links to SPG, } \\
\text { LBQ and HRH. }\end{array}$ \\
\hline Commando Spirit & $\begin{array}{l}\text { A private, profit-making company that contracts with the RMCT to run } \\
\text { fundraising events for them, taking a commission on all monies raised. }\end{array}$ \\
\hline
\end{tabular}


Table 2 First and second order themes with supporting evidence

\begin{tabular}{|c|c|}
\hline $\begin{array}{l}\text { Second-order } \\
\text { themes }\end{array}$ & $\begin{array}{l}\text { First-order themes and } \\
\text { supporting evidence }\end{array}$ \\
\hline \multicolumn{2}{|c|}{ Resource accumulation cycle } \\
\hline \multirow[t]{10}{*}{$\begin{array}{l}\text { Purpose (re) } \\
\text { articulation }\end{array}$} & $\begin{array}{l}\text { Original purpose and the repetition of its underlying agendas } \\
\text { "The charity abseil from the Shard is a total Good News Story for the Shard. In the last week alone, five } \\
\text { of our trustees (including the Duke of York) have received sponsorship pledges in excess of } £ 600,000 . " \\
\text { (CEO of TOBT, email to SPG) }\end{array}$ \\
\hline & $\begin{array}{l}\text { "At various points it looked as if; as though the role of the Trustees was going to be forgotten in this in } \\
\text { the urge to get more money out of other people for doing the same thing and [HRH's personal secretary] } \\
\text { and I had to repeatedly re-insert the broader challenge aspects of this back into it." (TOBT Trustee) }\end{array}$ \\
\hline & $\begin{array}{l}\text { "I think there was a little bit of trade off but acceptably, I mean the Trustee challenge thing wasn't to the } \\
\text { fore as I would have wanted it but it was there and it did work." TOBT Trustee. }\end{array}$ \\
\hline & $\begin{array}{l}\text { "Yes there'll be some brand awareness that comes off it but we're not justifying anything that we do } \\
\text { around brand awareness, this is all about a million quid for bursary." (TOBT Director) }\end{array}$ \\
\hline & $\begin{array}{l}\text { Purpose development to include new partnership } \\
\text { "If they, the Palace across all the Royals and I've seen this particularly from the Duke of Edinburgh's } \\
\text { office as well if they can leverage an event to benefit more than one charity they will do that." (TOBT } \\
\text { Trustee) }\end{array}$ \\
\hline & $\begin{array}{l}\text { "So this first couple of meetings at the Palace, thrashing out what the involvement would be, how we } \\
\text { could assist, what our role was and whether there was actually room for us." (Royal Marines PR) }\end{array}$ \\
\hline & $\begin{array}{l}\text { "I think it's an important element here that the Royal Marine Charity, we were thrust into that } \\
\text { relationship, we didn't know them at all." (TOBT Trustee) }\end{array}$ \\
\hline & $\begin{array}{l}\text { Evolving beliefs about publicity and the importance of PR } \\
\text { "One important point to make though is that any press/marketing must go through us first" (SPG } \\
\text { representative, email to TOBT CEO) }\end{array}$ \\
\hline & $\begin{array}{l}\text { "It was also about a game change in terms of the profile of Outward Bound. [...] it would certainly not, } \\
\text { as far as the Duke has been concerned, have been a success if all that would happen would be that you } \\
\text { raise the } 150 \text { and you didn't use that opportunity to, if you like remind the world what Outward Bound } \\
\text { stand for and indeed the Marines." (HRH's personal secretary) }\end{array}$ \\
\hline & $\begin{array}{l}\text { "The cost issue didn't surface adequately in the meeting at all and yet there was a lot of talk about the PR } \\
\text { and where we'd got to with it" (TOBT CFO) }\end{array}$ \\
\hline \multirow[t]{6}{*}{$\begin{array}{l}\text { Resource } \\
\text { framing }\end{array}$} & $\begin{array}{l}\text { Assessing resource requirements for evolving operational plans } \\
\text { "We're in a very different situation, you know a very different charity The Outward Bound Trust, I mean } \\
\text { they're a mature organisation, they're an international organisation, they have heavy hitting Trustees." } \\
\text { (Commando Spirit CEO) }\end{array}$ \\
\hline & $\begin{array}{l}\text { "I think [TOBT CEO] was very shrewd, he knew that [P-AR] had an interest with not only the Qatari } \\
\text { Royal Family that basically own The Shard but also that they have done work for the Duke of York. So } \\
\text { he very smartly put them into position to be the neutral PR Agency." (TOBT Head of PR) }\end{array}$ \\
\hline & $\begin{array}{l}\text { Understanding how to access key resources } \\
\text { "[The Mountaineer] and [High Ropes Expert] have worked together for nearly } 30 \text { years and, apart from } \\
\text { extremely distinguished mountaineering accomplishments, they have worked as safety consultants on } \\
\text { numerous projects ... involving skyscrapers, atriums, hot air balloons as well as mountain, desert and } \\
\text { jungle environments." (Extract from proposal document written by TOBT for the LBQ Board meeting in } \\
\text { Doha) }\end{array}$ \\
\hline & $\begin{array}{l}\text { "Well it was all dependent on the Duke getting permission from the Qatari owners of the Shard to do this } \\
\text { and it was never a done deal." (TOBT Trustee) }\end{array}$ \\
\hline & $\begin{array}{l}\text { "The Duke, partly by virtue of personality and partly by virtue of his position, is a really very effective } \\
\text { networker. The range of people he meets is vast and he has no hesitation in using that network in bringing } \\
\text { people together for a good cause, for the common good as it were." (TOBT Trustee) }\end{array}$ \\
\hline & $\begin{array}{l}\text { "The Duke's view, and I'm having sort of sat through it all now I think was correct, was that it's a more } \\
\text { powerful story where you've got the military alongside it." (HRH's private secretary) }\end{array}$ \\
\hline
\end{tabular}


Table 2 continued

\begin{tabular}{|c|c|}
\hline $\begin{array}{l}\text { Second-order } \\
\text { themes }\end{array}$ & $\begin{array}{l}\text { First-order themes and } \\
\text { supporting evidence }\end{array}$ \\
\hline \multicolumn{2}{|c|}{ Capability assembly cycle } \\
\hline \multirow[t]{3}{*}{ Anticipating } & $\begin{array}{l}\text { Working out roles in the transition from simple to multiple agendas } \\
\text { "This has been a slightly complicated process in the fact that the Royal Marines are our key partners } \\
\text { in delivering the abseil but because they can't receive money because they're a civil service, they have } \\
\text { a Charitable Trust Fund which is independently set up which does raise money on behalf of Marines." } \\
\text { (TOBT Project Manager) }\end{array}$ \\
\hline & $\begin{array}{l}\text { "You know it was so complicated to organise with the resources and the time scales and the people, } \\
\text { that everything was set up for one go at it." (The Mountaineer) }\end{array}$ \\
\hline & $\begin{array}{l}\text { "The Royal Marines, they came in and with [a logistics specialist Corporal], he came in and the way } \\
\text { that he structured everything as to how the rotas and the timetables would work, particularly who } \\
\text { needed to be where and when." (TOBT Project Manager) }\end{array}$ \\
\hline
\end{tabular}

\section{Managerial priorities in relation to the evolving PR purpose}

"The TOBT head of PR went to see the most senior Director at P-AR to inform them that they were 'wanted at the palace', and very quickly they became central to the stakeholder meetings and discussions." (Head of Marketing TOBT, discussion notes)

"Sellar's were quite clear as I understand it that major scale corporate sponsorship was not a goer because there was a risk of distracting from the brand of The Shard itself." (TOBT CFO)

"There's a really strong sense that [SPG head of PR] is a really critical stakeholder so we've got to make sure she's comfortable as we move towards the event." (TOBT Director)

Co-specializing Understanding and deploying operational expertise

"...the individual giving team in London have been out recruiting and they are masterful in terms of their expectation and management with people." (TOBT Director)

"Well really I've just been focussing on the systems and how we will do it. Putting the team together in terms of who and what their jobs will be. How we will manage people from a safety point of view." (High Ropes Expert)

\section{Deciding to separate resources (ropes) for separate fundraising}

"It eventually was resolved between me and Brigadier or Lieutenant Colonel in The Royal Marines, not in The Charitable Trust but The Royal Marines, where we said right there's 40 people going down this rope, these ropes, how are we going to divi it up." (TOBT CEO)

"because he's a one man band he chose to use Commando Spirit which is a commercial company. People don't realise this, they present themselves very well but actually they work on a commission basis." (TOBT Project Manager)

\section{Integrating Management integration and work flow}

"it was mainly about branding and what we needed to be included and I represented the Corp, The Royal Marines Charitable Trust Fund and also the Commando Spirit Appeal, making sure that the right logos were in and we had links [...] to those individual websites." (Royal Marines PR)

"In terms of the division of labour you've got [The Mountaineer] who's got overall responsibility and is the bridge between The Shard people and the operations, safety operation. There's [TOBT CEO] of course who is $[\ldots]$ in charge of everything [...] Nick will be managing the people and the movement of the people in the building, getting them to the right place." (High Ropes Expert)

\section{Understandings of roles and responsibility}

"it was, 'I'm holding you personally responsible for anything that goes wrong on the day"” (The Mountaineer, describing his final meeting with Irvine Sellar)

"Which is why you have one person sitting at the top who's in charge and has the only say so in terms of dangling people off a piece of rope" (Royal Marines Officer)

"I have huge amount of respect for [the Mountaineer] because I remember the meeting where he just, I felt he just gripped it...He was very clear to say I'm about the abseil, you know I'm leading the abseil. But within that he then helped to grip the rest of the project." (Commando Spirit CEO)

\section{Rapid response to late challenges}

"High-top Nike trainers had been selected and 50 pairs purchased [...] then an email arrived from Nike stating that their footwear was not suitable for abseiling [...] [The Mountaineer] knew they were fine, but it was clearly a liability thing. So, two days before the event, the TOBT office staff had to [...] go to Oxford Street for other trainers.' (Head of Marketing TOBT, discussion notes)

"And [TOBT Fundraiser] was still filling places. So he rang me on the Saturday and said look I've got two guys who can do it on Monday but they haven't made any of the training, if they fly in tomorrow morning can you train them on Sunday afternoon. So of course you know if those guys come that's another $£ 100,000$ in the coffers, it pays all the expenses you know." (The Mountaineer) 
Table 3 Event timeline

\begin{tabular}{|c|c|c|}
\hline Phase & Date & Summary of key events \\
\hline \multirow{4}{*}{ Phase 1} & 2011 & \\
\hline & $\begin{array}{l}\text { Pre- } \\
\text { December }\end{array}$ & $\begin{array}{l}\text { In September the Trustees of TOBT task The Mountaineer to come up with } \\
\text { proposals for fundraising events to generate a modest level of income, and } \\
\text { provide team building for the Trustee group. Ideas are to be presented at the } \\
\text { Dec } 2011 \text { Board Meeting. }\end{array}$ \\
\hline & December & $\begin{array}{l}\text { The Trustees meet at Buckingham Palace. HRH suggests that the event should } \\
\text { be an abseil from The Shard. HRH tasks himself to gain access to the building, } \\
\text { while the Mountaineer is tasked with assessing risk and feasibility. }\end{array}$ \\
\hline & $\begin{array}{l}\mathbf{2 0 1 2} \\
\text { January }\end{array}$ & $\begin{array}{l}\text { HRH negotiates access to the Shard building for the abseil with Sellar. They } \\
\text { agree that the Royal Marines will be operationally involved in the event, and } \\
\text { their charity will get some benefit from the fundraising. }\end{array}$ \\
\hline \multirow{3}{*}{ Phase 2} & \multirow{3}{*}{ February } & $\begin{array}{l}\text { The Mountaineer meets the Royal Marines and RMCT for the first time, at a } \\
\text { meeting at Buckingham Palace, chaired by HRH. The Mountaineer presents his } \\
\text { risk assessment and operational plans for the abseil, and it is agreed that he will } \\
\text { run the event. }\end{array}$ \\
\hline & & $\begin{array}{l}\text { During a meeting at Buckingham Palace the use of TOBT's and the Marine's } \\
\text { resources are discussed. Key differences in abseil expertise between } \\
\text { Mountaineers and Royal Marines are discovered. }\end{array}$ \\
\hline & & Provisional approval was obtained to use the Shard as a venue for the abseil. \\
\hline \multirow{4}{*}{ Phase 3} & $\begin{array}{l}\text { March } \\
\& \text { April }\end{array}$ & $\begin{array}{l}\text { Publicity for SPG emerges as an important new agenda. P-AR are appointed, } \\
\text { pro-bono, and begin attending all Buckingham Palace meetings. Various PR } \\
\text { activities are suggested that would reduce funds raised. Team development } \\
\text { intentions are relegated in favour of fund raising (Vignette 5). }\end{array}$ \\
\hline & $\begin{array}{l}\text { May } \\
\text { \& June }\end{array}$ & $\begin{array}{l}\text { The RMCT Brigadier has his first meeting with the fundraising Director of } \\
\text { TOBT. The CEO of TOBT and the Lieutenant Colonel of the Royal Marines } \\
\text { allocate a set number of descents to each charity to 'sell' to their own } \\
\text { participants. The RMCT appoint Commando Spirit to recruit abseilers and } \\
\text { manage their fundraising (Vignette 6). }\end{array}$ \\
\hline & July & $\begin{array}{l}\text { The Shard is officially opened by HRH on the 6th of July. The outside of the } \\
\text { building is now complete, although internally it is still a building site. The first } \\
\text { press release for The Descent of The Shard event is released globally by P-AR } \\
\text { on } 12 \text { July. }\end{array}$ \\
\hline & August & $\begin{array}{l}\text { TOBT and Commando Spirit are actively engaged in finding individuals } \\
\text { willing to participate in the event, and raise the required amounts of money. } \\
\text { Training events take place to teach all participants how to use the bespoke } \\
\text { abseiling equipment. }\end{array}$ \\
\hline Phase 4 & September & $\begin{array}{l}\text { On Saturday } 1 \text { st September the Mountaineer and his team have their first } \\
\text { chance to test the abseil from the top of The Shard. They identify risks on the } \\
\text { outside of the building that must be managed, as well as a need for additional } \\
\text { logistical support from the Royal Marines. On Monday 3rd September at } 7 \text { am } \\
\text { HRH is the first to abseil from The Shard. In total } 40 \text { abseils take place, raising } \\
£ 2.7 \mathrm{~m} \text {. }\end{array}$ \\
\hline
\end{tabular}


Figure 1 The cognitive foundations of capability development in temporary organizations

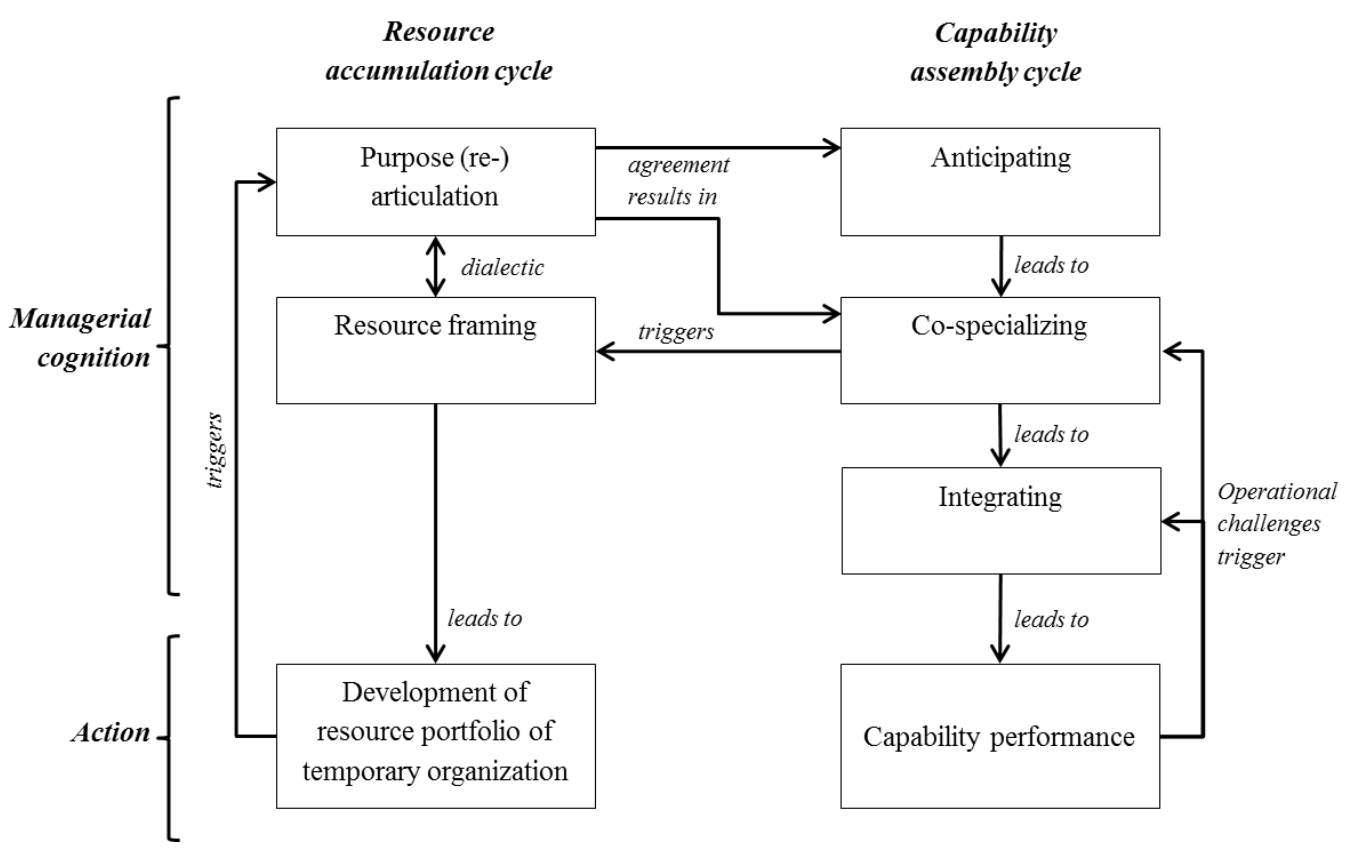

Table 4 Types of managerial cognition

\begin{tabular}{|c|c|c|}
\hline Cycle & Managerial cognition & Description \\
\hline \multirow[t]{2}{*}{$\begin{array}{l}\text { Resource } \\
\text { accumulation cycle }\end{array}$} & Purpose (re-) articulation & $\begin{array}{l}\text { Development of shared understanding amongst } \\
\text { stakeholders with regard to the purpose of the } \\
\text { organization }\end{array}$ \\
\hline & Resource framing & $\begin{array}{l}\text { Stakeholders' understanding of the types of resources } \\
\text { required, important resource gaps as well as well as } \\
\text { understanding of the value of particular resources to } \\
\text { fulfil the purpose of the organization }\end{array}$ \\
\hline \multirow[t]{3}{*}{$\begin{array}{l}\text { Capability } \\
\text { assembly cycle }\end{array}$} & Anticipating & $\begin{array}{l}\text { Development of assumptions and scenarios about how } \\
\text { resources will be put to use and how stakeholders will } \\
\text { interact in order to fulfil purpose }\end{array}$ \\
\hline & Co-specializing & $\begin{array}{l}\text { Development of shared understanding regarding the } \\
\text { complementary roles of particular stakeholders and } \\
\text { the complementary use of resources }\end{array}$ \\
\hline & Integrating & $\begin{array}{l}\text { Development of shared process knowledge across } \\
\text { stakeholders regarding the sequence of actions that } \\
\text { needs to be performed }\end{array}$ \\
\hline
\end{tabular}

